\title{
High Speed Direct Modulation of a Heterogeneously Integrated InP/SOI DFB Laser
}

\author{
Amin Abbasi, Christos Spatharakis, Giannis Kanakis, Nuno Sequeira André, Hadrien Louchet, \\ Andrew Katumba, Jochem Verbist, Hercules Avramopoulos, Peter Bienstman, Xin Yin, \\ Johan Bauwelinck, Gunther Roelkens, and Geert Morthier
}

(Top-Scored)

\begin{abstract}
An integrated laser source to a silicon photonics circuit is an important requirement for optical interconnects. We present direct modulation of a heterogeneously integrated distributed feedback laser on and coupled to a silicon waveguide. We demonstrate a $28 \mathrm{~Gb} / \mathrm{s}$ pseudo-random bit sequence non-returnto-zero data transmission over $2 \mathrm{~km}$ non-zero dispersion shifted fiber with a 1-dB power penalty. Additionally, we show 40-Gb/s duobinary modulation generated using the bandwidth limitation of the laser for both back-to-back and fiber transmission configurations. Furthermore, we investigate the device performance for the pulse amplitude modulation (PAM-4) at $20 \mathrm{GBd}$ for high-speed short-reach applications.
\end{abstract}

Index Terms-Direct modulation, distributed feedback lasers, duobinary, hybrid integrated circuit fabrication, pulse amplitude modulation (PAM-4).

\section{INTRODUCTION}

$\mathbf{T}$ O MEET datacenter requirements for server-to-server communication at high bitrate and low-cost, optical interconnects based on intensity modulation and direct detection are gaining popularity [1], [2]. While the direct modulation of vertical cavity surface emitting lasers (VCSELs) can fulfill

Manuscript received October 26, 2015; revised December 15, 2015; accepted December 15, 2015. Date of publication January 17, 2016; date of current version March 3, 2016. This work was supported by the Belgian IAP network Photonics@be 14/GOA/034, the UGent special research fund BOF, and MIRAGE project.

A. Abbasi, A. Katumba, P. Bienstman, G. Roelkens, and G. Morthier are with the Department of Information Technology, Photonics Research Group, Interuniversity Microelectronics Center and Center for Nano and Biophotonics, Ghent University, Ghent B-9000, Belgium (e-mail: aamin@intec.ugent. be; andrew.katumba@intec.ugent.be; Peter.Bienstman@ugent.be; gunther. roelkens@intec.ugent.be; geert.morthier@intec.ugent.be).

C. Spatharakis, G. Kanakis, and H. Avramopoulos are with the School of Electrical and Computer Engineering, National Technical University of Athens, Zografou, Athens GR15773, Greece (e-mail: cspatha@mail.ntua.gr; giankan@mail.ntua.gr; hav@mail.ntua.gr).

N. S. André and H. Louchet are with the VPIphotonics, Berlin 10587, Germany (e-mail: nuno.andre@vpiphotonics.com; hadrien.louchet@ vpiphotonics.com).

J. Verbist is with the Department of Information Technology, Design Group, Ghent University-iMinds-Interuniversity Microelectronics Center, Ghent 9000, Belgium and also with the Department of Information Technology, Photonics Research Group, Interuniversity Microelectronics Center and Center for Nano and Biophotonics, Ghent University, Ghent B-9000, Belgium (e-mail: jochem.verbist@intec.ugent.be).

$\mathrm{X}$. Yin and J. Bauwelinck are with the Department of Information Technology, Design Group, Ghent University—iMinds-Interuniversity Microelectronics Center, Ghent 9000, Belgium (e-mail: xin.yin@intec.ugent.be; johan. bauwelinck@intec.ugent.be).

Color versions of one or more of the figures in this paper are available online at http://ieeexplore.ieee.org.

Digital Object Identifier 10.1109/JLT.2015.2510868 most of the requirements for short-reach links $(<100 \mathrm{~m})$ [2], [3], given their low threshold current and fast dynamics, realizing high aggregate bitrate transceivers requires wavelength division multiplexing (WDM), which is not trivial with VCSELs. Moreover, they typically have lower output power [2]-[4]. For applications that require high optical power and stable single mode operation, distributed feedback (DFB) lasers present an attractive alternative [5], [6] and they are easily integrated into a WDM transmitter.

High performance directly modulated DFB lasers on an InP platform and bonded to a silicon substrate have been demonstrated recently [5]-[7]. At the same time, silicon photonics is emerging as the platform of choice for the integration of photonics with electronic integrated circuits because of its potential for low cost fabrication and dense integration capacity. Intensive research is going on towards the integration of photonic active components, such as laser diodes [8], [9], photodiodes [10] and modulators [11], on a silicon photonics platform. Given the mentioned advantages of silicon photonics it would be desirable to have directly modulated transmitters-for instance the DFB laser in this work-with a high modulation bandwidth coupled to a silicon photonic integrated circuit. Heterogeneous integration has emerged as an attractive approach to realize this integration, as it is relatively easily scaled to large arrays of devices [12].

So far however, only a limited number of results on the high speed direct modulation capabilities of heterogeneously integrated laser diodes have been published. In [13], a hybrid DFB laser was directly modulated at $12.5 \mathrm{~Gb} / \mathrm{s}$ with an extinction ratio of $2.8 \mathrm{~dB}$ for a $1.5 \mathrm{~V}$ voltage swing. In [14], a much higher bitrate of $21.4 \mathrm{~Gb} / \mathrm{s}$ is demonstrated using a heterogeneously integrated tunable laser, exploiting an external cavity resonance (photon-photon resonance). Recently, $28 \mathrm{~Gb} / \mathrm{s} \mathrm{NRZ}$ direct modulation of hybrid integrated III-V-on-silicon DFB has been demonstrated by us [15].

In this paper, we present our recent progress on the direct modulation of a hybrid InP/SOI DFB laser using different modulation formats. First, a brief explanation of the fabrication process and the static characteristics of the device are presented in Section II. Section III deals with the NRZ modulation scheme and contains corresponding BER results for back-to-back (B2B) and for transmission over a $2 \mathrm{~km}$ non-zero dispersion shifted fiber (NZ-DSF). Section IV discusses results for multi-level pulse amplitude modulation (PAM) and duobinary modulation at $40 \mathrm{~Gb} / \mathrm{s}$. Duobinary modulation, generated using the 


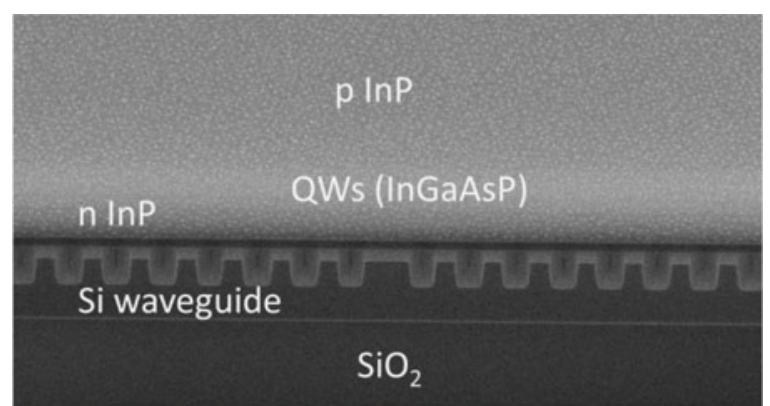

(a)

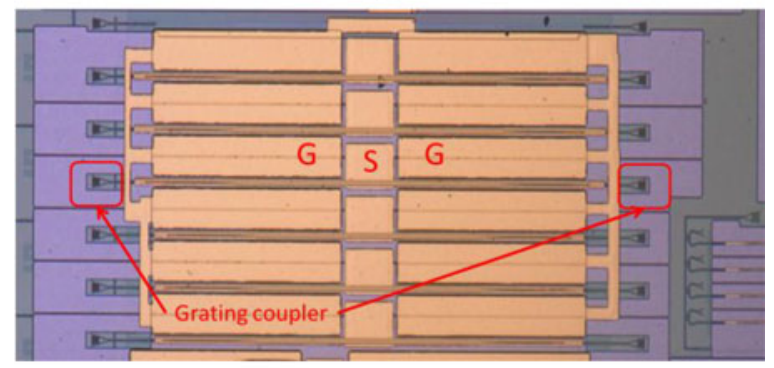

(b)

Fig. 1. Longitudinal cross section of the device (top), top view of the sample (bottom), GSG pads and grating couplers are indicated for one laser.

bandwidth limitation of the laser, provides a viable alternative to reach a bitrate of $40 \mathrm{~Gb} / \mathrm{s}$. In all cases, we show recorded eye diagrams together with the corresponding BER versus optical received power characteristics.

\section{FABRICATION AND STATICS CHARACTERISTICS}

The fabricated hybrid III-V-on-silicon DFB lasers are depicted in Fig. 1. Each laser consists of a DFB grating defined in a $400 \mathrm{~nm}$ thick silicon waveguide layer using $193 \mathrm{~nm}$ deep UV lithography, with the III-V gain region bonded on top. The InP epitaxial layer stack is adhesively bonded to the patterned and planarized silicon-on-insulator (SOI) using divinylsiloxane-bisbenzocyclobutene. The coupling coefficient of the laser can be controlled by varying the thickness of the bonding layer. The designed coupling coefficient is $135 \mathrm{~cm}^{-1}$ and the DFB grating length is $340 \mu \mathrm{m}$. Taper structures are used to couple the DFB to the passive silicon waveguide layer. The longitudinal crosssection of the device is shown in Fig. 1(a). Fig. 1(b) shows the top view of the fabricated devices connected to grating couplers for fiber-chip interfacing. A $-7 \mathrm{~dB}$ fiber-to-chip coupling efficiency was obtained. The separation between the III-V and the silicon waveguide is $50 \mathrm{~nm}$ and the gratings are etched $180 \mathrm{~nm}$ deep and have a duty cycle of $50 \%$. The III-V layer stack consists of six InGaAsP quantum wells (photoluminescence peak at $1.55 \mu \mathrm{m})$ sandwiched between InGaAsP separate confinement heterostructure layers (bandgap wavelength $1.17 \mu \mathrm{m}$ ) and InP cladding layers.

Static measurements were performed to verify the laser's optical power and electrical properties. Fig. 2 shows $L-I-V$ curves for the DFB laser and the optical spectrum at $100 \mathrm{~mA}$ bias current (see Fig. 2, inset) measured at $20^{\circ} \mathrm{C}$. The side mode suppression ratio is more than $45 \mathrm{~dB}$. The laser operates at $1566 \mathrm{~nm}$,

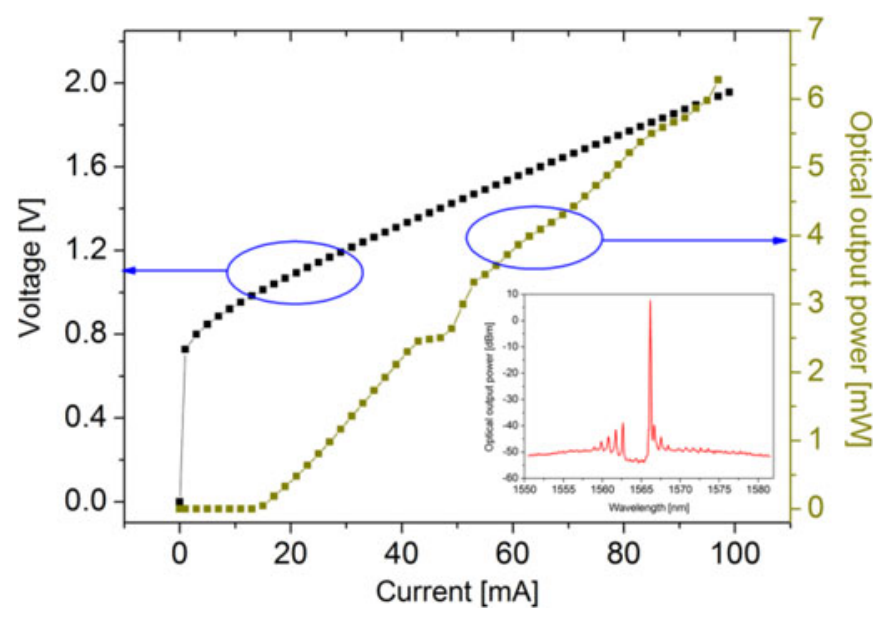

Fig. 2. $L-I-V$ curves and optical spectrum (inset) of the DFB laser.

close to the gain peak of the laser structure. The average optical power in the $\mathrm{Si}$ waveguide is $6 \mathrm{~mW}$ at $100 \mathrm{~mA}$ bias current. The kink in the $L-I$ curve is attributed to a mode hop from the shorter wavelength band edge mode of the DFB laser to the longer wavelength mode due to device heating (an effect which only occurs in $\mathrm{CW}$ operation and not under dynamic operation, as verified by monitoring the laser spectrum during the large signal measurements described later in the paper). The laser threshold current $I_{\mathrm{th}}$ is $17 \mathrm{~mA}$.

\section{NRZ MODULATION}

The large signal modulation measurements were performed by using an SHF 12100B pulse pattern generator (PPG) for variable bitrate measurements with adjustable pattern lengths. The output of the PPG was amplified by an SHF S807 broadband RF amplifier. An RF-voltage of $2 \mathrm{~V}_{\mathrm{pp}}$ (assuming a $50 \Omega$ load) was applied to the laser to realize large signal modulation. As the laser is not $50 \Omega$ terminated a much lower voltage swing $(<1 \mathrm{~V})$ on the laser is expected. Eye diagrams were measured using a Tektronix DSA 8300 sampling oscilloscope. Eye diagrams were measured using a Sumitomo photodiode with a packaged limiting transimpedance amplifier at the receiver side and are shown in Fig. 3. Electrical NRZ signals with different PRBS pattern lengths were used to directly modulate the DFB laser. As can be seen in Fig. 3(a), the eyes are open at $28 \mathrm{~Gb} / \mathrm{s}$ even after propagating through a $2 \mathrm{~km} \mathrm{NZ-DSF}$ with a dispersion coefficient of $4.5-6 \mathrm{ps} / \mathrm{nm} \cdot \mathrm{km}$ at $1565 \mathrm{~nm}$. A $2 \mathrm{~dB}$ extinction ratio was measured in the $\mathrm{B} 2 \mathrm{~B}$ configuration. Less than $1 \mathrm{~dB}$ power penalty at BER of $10^{-9}$ was measured for transmission over $2 \mathrm{~km} \mathrm{NZ-DSF}$ at $28 \mathrm{~Gb} / \mathrm{s}$ using a data stream length of $2^{7}-1$.

Degradation can be observed for longer word length, as was also observed and is also explained in other works [16], [17]. Using encoding methods such as $8 \mathrm{~b} / 10 \mathrm{~b}$ may be useful to reduce this pattern effect [18]. With $8 \mathrm{~b} / 10 \mathrm{~b}$, each eight bits of data is mapped into ten bits for transmission. It is well balanced, with minimal deviation from the occurrence of an equal number of 1 and 0 bits across any sequence. 


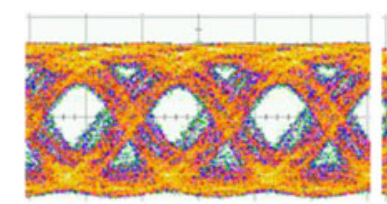

(a)

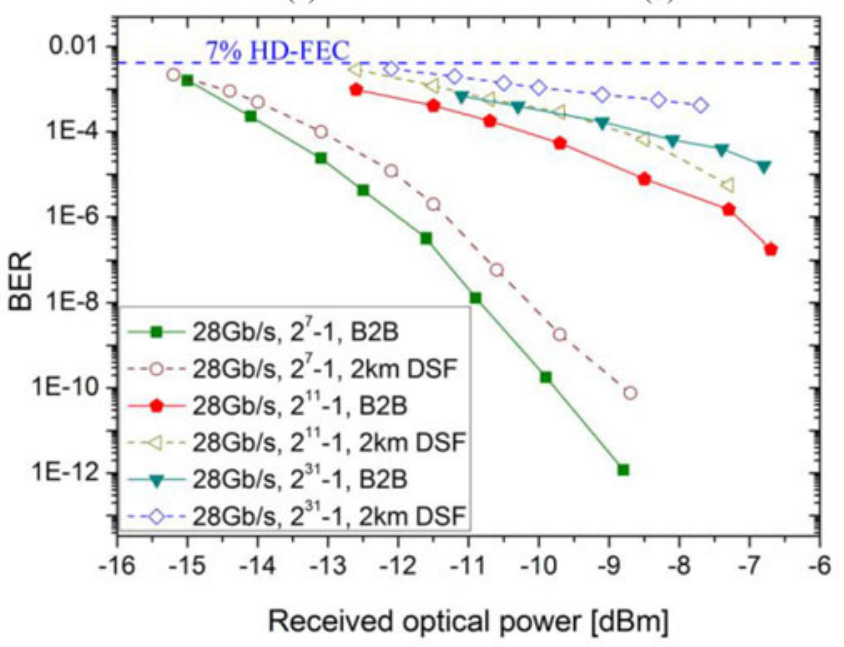

(c)

Fig. 3. Eye diagrams for B2B (a) and after $2 \mathrm{~km}$ NZ-DSF fiber transmission, (b) at $28 \mathrm{~Gb} / \mathrm{s}$ using a $2^{11}-1$ data pattern length (bias current of $100 \mathrm{~mA}$ at $20{ }^{\circ} \mathrm{C}$ ), (c) BER curves for different PRBS pattern lengths.

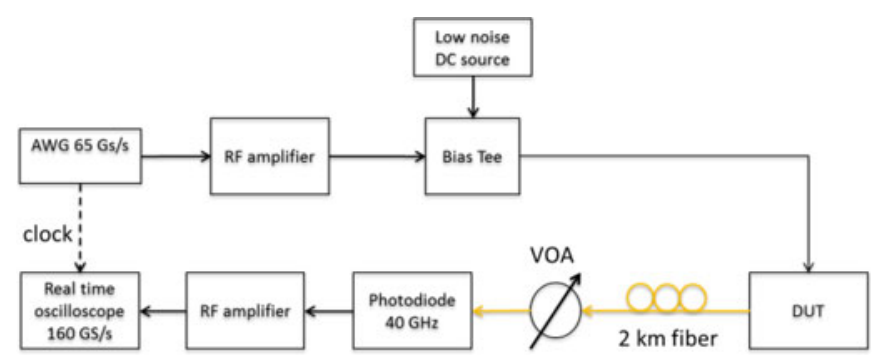

Fig. 4. Experimental setup used to characterize the advanced modulation

\section{DUOBINARY AND PAM-4 MODULATION}

The experimental setup used to characterize the advanced modulation format performance of the devices is shown in Fig. 4. The electrical signal is generated by a Keysight M8195A arbitrary waveform generator and is then amplified by an SHF-S708 $\mathrm{RF}$ amplifier. A low noise dc current is combined with the RF data using a bias-tee and the output is used to drive the laser through a GSG RF probe. The laser bias current is set around $100 \mathrm{~mA}$ and a $1.5 \mathrm{~V}_{\mathrm{pp}}$ (assuming a $50 \Omega$ load) data signal is used. The optical data signal is propagated through a $2 \mathrm{~km}$ NZ-DSF. At the receiver side, a variable optical attenuator and a $40 \mathrm{GHz}$ Discovery Semiconductors photodiode together with a SHF high-speed amplifier are used to boost the received signal to the desired level. The electrical data is captured by a Keysight DSA-Z634 $63 \mathrm{GHz}$ real time oscilloscope. The saved data was then processed off-line for BER estimation with and without equalization.

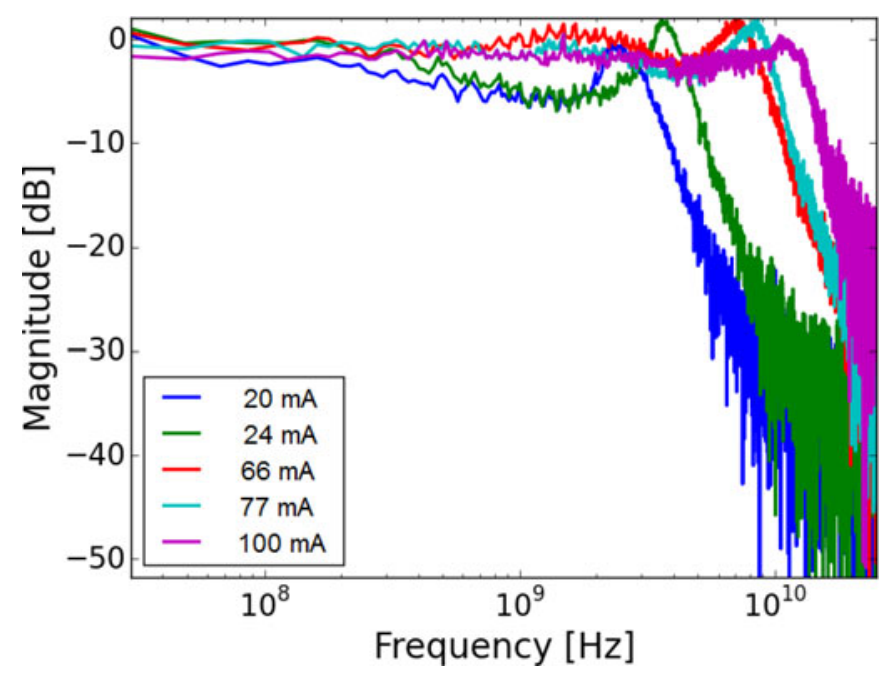

Fig. 5. Electro-optic response of the laser at different bias currents.

Three level duobinary data modulation and detection using lower bandwidth devices have been reported recently [19]. Since the laser's $S_{21}$ electro-optic response looks similar to the fifth order Bessel function with $3 \mathrm{~dB}$ bandwidth of $15 \mathrm{GHz}$ (Fig. 5), we were able to exploit this fact and generate electrical duobinary using the laser as the low pass filter. The duobinary signal presents three levels (see Fig. 6). The lower and upper signal levels represent sequences of 0 and $1 \mathrm{~s}$, respectively whereas a transition from 0 to 1 or from 1 to 0 is mapped on the central level. As such, knowledge of the previous transmitted bit is needed in order to decode the current one but differential coding can be used to prevent error propagation.

Eye diagrams for $40 \mathrm{~Gb} / \mathrm{s}$ duobinary modulation are shown in Fig. 6. In Fig. 6(a), (b) eye diagrams for a pattern length of $2^{7}-1$ for B2B and $2 \mathrm{~km}$ NZ-DSF transmission are shown respectively. Similarly, results for a pattern length of $2^{15}$ are given in Fig. 6(c), (d). Signal post processing, decoding and BER estimation were performed offline using VPIlabExpert (see Fig. 6(e)). The original signal or the electrical B2B signal was used to extract the original bit sequence and then this information was applied to create the PDF (probability density functions) for the three levels of the optical received signal. The BER was then estimated using Chi2 curve fitting.

Through the use of a low-complexity, 10-tap feed forward equalizer (FFE), the BER can be improved. From Fig. 6(e), when equalization is applied and for a $2^{7}-1$ pattern, one can estimate less than $1.5 \mathrm{~dB}$ power penalty for a transmission over a $2 \mathrm{~km}$ NZ-DSF fiber compared with the B2B configuration at $7 \%$ hard decision FEC limit.

An alternative approach to reach a higher bit rate is to use PAM [3], [4]. The eye diagrams for 20 GBd PAM-4 B2B and after $2 \mathrm{~km}$ NZ-DSF transmission measurements are depicted in Fig. 7. PRBS sequence lengths of $2^{7}-1$ and $2^{15}$ are used. In Fig. 7(a), (b), eye diagrams for a word length of $2^{7}-1$ in B2B configuration and after $2 \mathrm{~km}$ of transmission over NZ-DSF are shown, respectively. The same is depicted in Fig. 7 (c), (d) for a word length of $2^{15}$. Comparing the eye diagrams B2B and after 


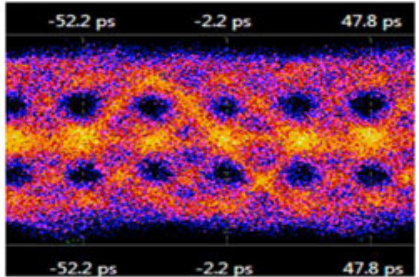

(a)

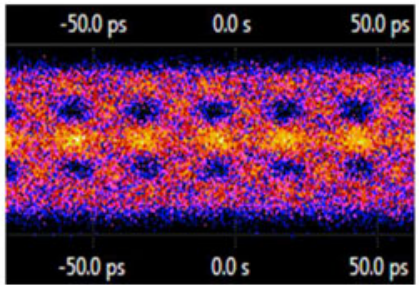

(c)

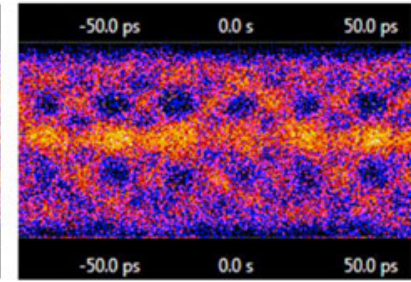

(b)

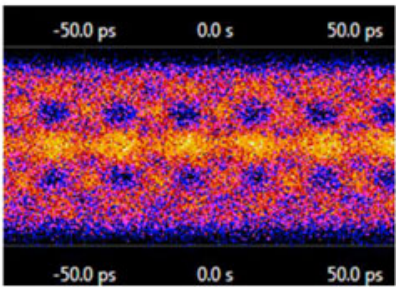

(d)

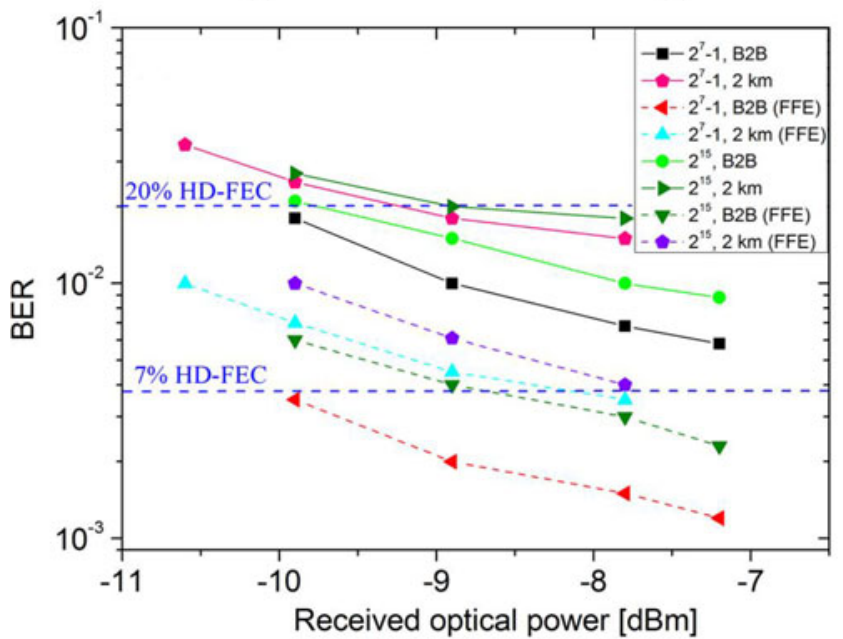

(e)

Fig. 6. (a) and (b) Eye diagrams for duobinary modulation at $40 \mathrm{~Gb} / \mathrm{s}$ in B2B configuration and after $2 \mathrm{~km}$ of transmission over NZ-DSF for a PRBS length of $2^{7}-1$ and (c) and (d) for a length of $2^{15}$ (e) BER measurements for B2B, and 2 km NZ-DSF configuration.

$2 \mathrm{~km}$ NZ-DSF transmission, a deterioration can be observed, linked to the interaction between chromatic dispersion in the fiber and the inherent chirp of the laser. The resulting BER evaluated for both PRBS pattern lengths in the B2B and $2 \mathrm{~km}$ fiber transmission cases are presented in Fig. 7(e).

In the case of PAM-4, offline signal processing in MATLAB was used. The processing consisted of symbol clock recovery, equalization, symbol slicing, and finally BER measurement by error counting. Similarly to the duobinary case, 10-tap FFE was used to eliminate the channel effect on the signal. The normalized least mean square algorithm was employed to determine the equalizer taps. As shown in Fig. 7(e), the performance is significantly improved when equalization is performed. Based on these measurements one may conclude that the performance of PAM-4 is slightly better than that of duobinary for the same bitrate. However one should take into account that different methods were used to evaluate the BER for the two modulation formats. The results indicate that both schemes can be equally

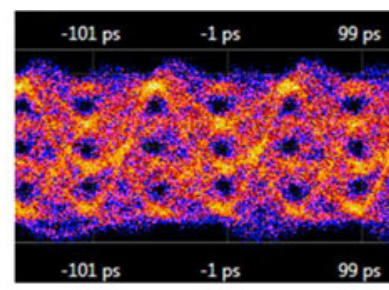

(a)

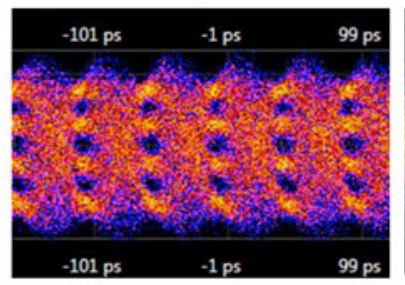

(c)

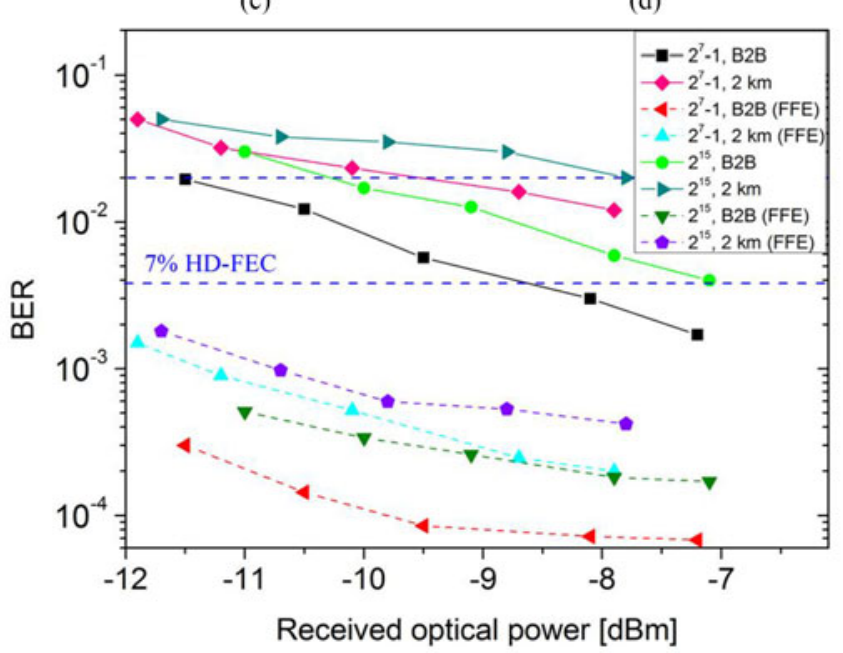

(e)

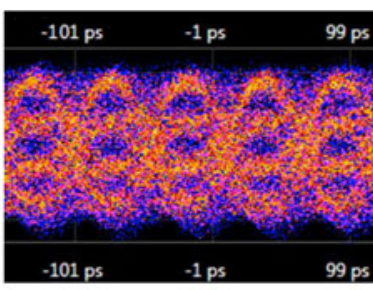

(b)

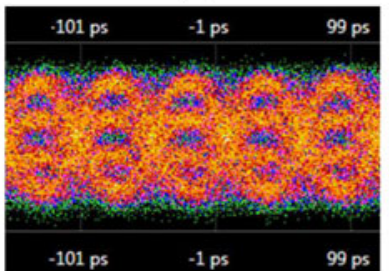

(d)
Fig. 7. (a) and (b) Eye diagrams for PAM-4 at $20 \mathrm{GBd}$ in B2B configuration and after $2 \mathrm{~km}$ of transmission over NZ-DSF for a PRBS length of $2^{7}-1$ and (c) and (d) for a length of $2^{15}$. BER measurements for B2B and $2 \mathrm{~km}$ NZ-DSF configuration (bottom).

important to boost a direct modulation laser's performance for short reach links in datacenters.

\section{CONCLUSION}

A InP membrane DFB laser, heterogeneously integrated on SOI has been realized for high-speed direct modulation. $28 \mathrm{~Gb} / \mathrm{s}$ NRZ data transmission over a $2 \mathrm{~km}$ NZ-DSF using a $2^{7}-1$ PRBS pattern was demonstrated with a power penalty of only $1 \mathrm{~dB}$ (BER 1e-9). In order to overcome the speed limit of the laser, duobinary and PAM-4 modulation experiments were performed at $40 \mathrm{~Gb} / \mathrm{s}$.

BER results indicate that PAM-4 is a slightly better solution than the duobinary scheme. Also PAM-4 is discussed in the IEEE $802.3 \mathrm{bs} 400 \mathrm{~Gb} / \mathrm{s}$ Ethernet task force as the next standard for 2 and $10 \mathrm{~km}$ 400G-Ethernet [20]. This indicates that PAM-4 based direct modulation is going to be an important optical modulation scheme for datacenter interconnects. On the other hand, using an array of NRZ modulated DFB lasers would enable the realization of $4 \times 28 \mathrm{GbE}$ wavelength division multiplexed 
or parallel optics transceivers. Further modulation speed improvement can be realized by wavelength detuning from the gain peak, better cooling, an optimized device geometry (e.g., by electrically disconnecting the taper amplifiers from the DFB laser section and reducing the laser active area resulting in a lower $R C$ time constant) and close integration with a proper low impedance laser driver chip. Using Al-containing quaternary materials in the active region, which have higher differential gain coefficient, could further improve the high speed (as well as thermal) properties of the device.

\section{ACKNOWLEDGMENT}

The authors would like to thank the L. V. Landschoot for SEM images.

\section{REFERENCES}

[1] H. Liu, C. F. Lam, and C. Johnson, "Scaling optical interconnects in datacenter networks opportunities and challenges for WDM," in Proc. IEEE Symp. High Perform. Interconnects, 2010, pp. 113-116.

[2] K. Iga, "Surface-emitting laser-its birth and generation of new optoelectronics field," IEEE J. Sel. Topics Quantum Electron., vol. 6, no. 6, pp. 1201-1215, Nov./Dec. 2000.

[3] F. Karinou, C. Prodaniuc, N. Stojanovic, M. Ortsiefer, A. Daly, R. Hohenleitner, B. Kögel, and C. Neumeyr, "Directly PAM-4 modulated 1530-nm VCSEL enabling $56 \mathrm{~Gb} / \mathrm{s} / \lambda$ data-center interconnects," IEEE Photon. Technol. Lett., vol. 27, no. 17, pp. 1872-1875, Sep. 2015.

[4] R. Rodes, M. Mueller, B. Li, J. Estaran, J. B. Jensen, T. Gruendl, M. Ortsiefer, C. Neumeyr, J. Rosskopf, K. J. Larsen, M.-C. Amann, and I. T. Monroy, "High-speed $1550 \mathrm{~nm}$ VCSEL data transmission link employing 25 GBd 4-PAM modulation and hard decision forward error correction," J. Lightw. Technol., vol. 31, no. 4, pp. 689-695, Feb. 2013.

[5] W. Kobayashi, T. Ito, T. Yamanaka, T. Fujisawa, Y. Shibata, T. Kurosaki, M. Kohtoku, T. Tadokoro, and H. Sanjoh, "50-Gb/s direct modulation of 1.3- $\mu \mathrm{m}$ InGaAlAs-based DFB laser with ridge waveguide structure," IEEE J. Sel. Top. Quantum Electron., vol. 19, no. 4, p. 1500908, Jul./Aug. 2013.

[6] T. Nakajima, T. Fukamachi, M. Akashi, A. Nakamura, Y. Sakuma, S. Hayakawa, R. Washino, M. Mukaikubo, K. Okamoto, K. Motoda, K. Naoe, K. Nakahara, S. Tanaka, and K. Uomi, "25.8 Gbps error free transmission over $10 \mathrm{~km}$ at wavelengths from 1271 to $1331 \mathrm{~nm}$ by uncooled (25 to $85 \mathrm{C}$ ) directly modulated DFB Lasers for 100G-CWDM4," presented at the Optical Fiber Communication Conf., Los Angeles, CA, USA, 2015, Paper Th1G.6.

[7] S. Matsuo, T. Fujii, K. Hasebe, K. Takeda, T. Sato, and T. Kakitsuka, "Directly modulated buried heterostructure DFB laser on $\mathrm{SiO} / \mathrm{Si}$ substrate fabricated by regrowth of InP using bonded active layer,' Opt. Exp., vol. 22 , no. 10 , pp. 12139-12147, 2014.
[8] A. W. Fang, E. Lively, Y. H. Kuo, D. Liang, and J. E. Bowers, "A distributed feedback silicon evanescent laser," Opt. Exp., vol. 16, no. 7, pp. 4413-4419, 2008.

[9] S. Keyvaninia, S. Verstuyft, L. Van Landschoot, F. Lelarge, G.-H. Duan, S. Messaoudene, J. M. Fedeli, T. De Vries, B. Smalbrugge, E. J. Geluk, J. Bolk, M. Smit, G. Morthier, D. Van Thourhout, and G. Roelkens, "Heterogeneously integrated III-V/silicon distributed feedback lasers," Opt. Lett., vol. 38, no. 24, pp. 5434-5437, 2013.

[10] L. Vivien, J. Osmond, J. M. Fédéli, D. Marris-Morini, P. Crozat, J. F. Damlencourt, E. Cassan, Y. Lecunff, and S. Laval, " 42 GHz p.i.n Germanium photodetector integrated in a silicon-on-insulator waveguide," Opt. Exp., vol. 17, no. 8, pp. 6252-6257, 2009.

[11] S. Srinivasan, M. Pantouvaki, S. Gupta, H. Chen, P. Verheyen, G. Lepage G. Roelkens, K. Saraswat, D. Van Thourhout, P. Absil, J. Van Campenhout, "56Gb/s germanium waveguide electro-absorption modulator," J. Lightw. Technol., vol. PP, no. 99, pp. 1-1, 2015, to be published.

[12] L. Vivien and L. Pavesi, Handbook of Silicon Photonics. Boca Raton, FL, USA: CRC Press, 2013, pp. 554-603.

[13] C. Zhang, S. Srinivasan, Y. Tang, M. J. R. Heck, M. L. Davenport, and J. E. Bowers, "Low threshold and high speed short cavity distributed feedback hybrid silicon lasers," Opt. Exp., vol. 22, no. 9, pp. 10202-10209, 2014.

[14] G. de Valicourt, G. Levaufre, Y. Pointurier, A. Le Liepvre, J.-C. Antona, C. Jany, A. Accard, F. Lelarge, D. Make, and G.-H. Duan, "Direct modulation of hybrid-integrated InP/Si transmitters for short and long reach access network," J. Lightw. Technol., vol. 33, no. 8, pp. 1608-1616, Apr. 2015.

[15] A. Abbasi, J. Verbist, J. V. Kerrebrouck, F. Lelarge, G. Duan, X. Yin, J. Bauwelinck, G. Roelkens, and G. Morthier, " $28 \mathrm{~Gb} / \mathrm{s}$ direct modulation heterogeneously integrated C-band InP/SOI DFB laser," Opt. Exp., vol. 23, no. 20, pp. 26479-26485, 2015.

[16] J. S. Gustavsson, A. Haglund, J. Bengtsson, and A. Larsson, "Highspeed digital modulation characteristics of oxide-confined vertical-cavity surface-emitting lasers-numerical simulations consistent with experimental results," IEEE J. Quantum Electron., vol. 38, no. 8, pp. 1089-1096, Aug. 2002.

[17] H. Zhu, Y. Xia, and J.-J. He, "Pattern dependence in high-speed Q-modulated distributed feedback laser," Opt. Exp., vol. 23, no. 9, pp. 11887-11897, 2015.

[18] A. Chiuchiarelli, M. J. Fice, E. Ciaramella, and A. J. Seeds, "Effective homodyne optical phase locking to PSK signal by means of $8 \mathrm{~b} / 10 \mathrm{~b}$ line coding," Opt. Exp., vol. 19, no. 3, pp. 1707-1712, 2011.

[19] Z. Li, L. Yi, X. Wang, and W. Hu, " 28 Gb/s duobinary signal transmission over $40 \mathrm{~km}$ based on $10 \mathrm{GHz}$ DML and PIN for $100 \mathrm{~Gb} / \mathrm{s}$ PON," Opt. Exp., vol. 23, no. 16, pp. 20249-20256, 2015.

[20] (2015, Jan.). Interim Atlanta, GA, USA. Moving Forward. [Online]. Available: http://www.ieee802.org/3/bs/public/15_01/ambrosia_3bs_01_ 0115.pdf

Authors' biographies not available at the time of publication. 